\title{
Infection-free rates and Sequelae predict factors in bone transportation for infected tibia: a systematic review and meta-analysis
}

\author{
Zhen Zhang ${ }^{1,2}$, W. Benton Swanson ${ }^{2}$, Yan-Hong Wang ${ }^{3}$, Wei Lin ${ }^{4}$ and Guanglin Wang ${ }^{1 *}$ (D
}

\begin{abstract}
Background: Tibia infected nonunion and chronic osteomyelitis are challenging clinical presentations. Bone transportation with external or hybrid fixators (combined external and internal fixators) is versatile to solve these problems. However, the infection-free rates of these fixator systems are unknown. Additionally, the prognosis factors for results of bone transportation are obscure. Therefore, this systematic review and metaanalysis was conducted to answer these questions.

Methods: A systematic review was conducted following the PRISMA-IPD guidelines. Relevant publications from January 1995 to September 2018 were compiled from Medline, Embase, and Cochrane. The infectionfree rates of external and hybrid fixators were achieved by synthesizing aggregate data and individual participant data (IPD). IPD was analyzed by two-stage method with logistical regression to identify prognosis factors of sequelae.

Results: Twenty-two studies with 518 patients were identified, including 11 studies with 167 patients' IPD, and 11 studies with 351 patients' aggregate data. The infection-free rate of hybrid fixator group was 86\% (95\%Cl: $79-$ 94\%), lower than that of external fixator which was $97 \%$ (95\%Cl: $95-98 \%)$ ). The number of previous surgeries was found predict factor of bone union sequelae $(p=0.04)$ and function sequelae $(p<0.01)$; The external fixation time was found predict factor of function sequelae $(p=0.015)$.

Conclusions: Hybrid fixators may be associated with a greater risk of infection-recurrence in the treatment of tibia infected nonunion and chronic osteomyelitis. The number of previous surgeries and external fixation time can be used as predictors of outcomes. Proper fixators and meticulously designed surgery are important to avoid unexpected operations and shorten external fixation time.
\end{abstract}

Keywords: Bone transportation, Infection-free rate, Predict factor of Sequelae

\section{Background}

Tibial infected nonunion and chronic posttraumatic osteomyelitis are common clinical presentations which pose substantial burdens on both patients and society $[1$, 2]. However, their treatment remains a large challenge; most cases are associated with infection caused by antibiotic-resistant bacteria, bone and soft tissue loss, deformities, and limb-length discrepancy [3, 4]. Many patients suffer from multiple operations due to more

\footnotetext{
*Correspondence: wangglfrank@hotmail.com

'Department of Orthopedics, West China Hospital, Sichuan University, No. 37 , Guoxue Lane, Wuhou District, Chengdu 610041, Sichuan Province, China Full list of author information is available at the end of the article
}

than one stage of treatment and associated complications $[5,6]$, especially the reoccurring infection which may be refractory and lead to amputation [7-9]. To achieve an infection-free result, radical debridement is necessary, but massive skeletal defects also result as a consequence [9]. Bone transport, based on principles of distraction osteogenesis, could tackle segmental bone defects and coexisting problems of lone bone infection simultaneously. The procedure of bone transportation could be divided into distraction and consolidation phases: After corticectomy in metaphysis, the lost tissue is compensated by gradual distraction of healthy bone segment towards the defect site, and consequent consolidation follows when bone

(c) The Author(s). 2018 Open Access This article is distributed under the terms of the Creative Commons Attribution 4.0 International License (http://creativecommons.org/licenses/by/4.0/), which permits unrestricted use, distribution, and reproduction in any medium, provided you give appropriate credit to the original author(s) and the source, provide a link to the Creative Commons license, and indicate if changes were made. The Creative Commons Public Domain Dedication waiver (http://creativecommons.org/publicdomain/zero/1.0/) applies to the data made available in this article, unless otherwise stated. 
ends meet $[10,11]$.During the phases of distraction and consolidation in bone transportation technique, osseous stability is provided by various fixator systems [12].

However, factors related to fixator choice for infected tibia is still obscure $[8,13]$. Among fixators, the most commonly used are external frames including circular and mono-lateral fixators. The external frames allow for early weight bearing and maintenance of tibia length during treatment. Nevertheless, external fixators suffer from complications associated with long-time external fixation, such as pin site infection and joint stiffness [14]. To shorten the external fixation time, several researchers have combined internal fixators with external frames for bone transportation during distraction and/or consolidation phases [13, 15-19]. This "hybrid fixator" system facilitates early removal of the external frame, helps maintain alignment, and prevents refracture [17, 20]. Despite its advantages, the hybrid fixators are suspected to be associated with a greater risk of infection recurrence which is worrisome for both clinicians and patients $[8,21]$. During treatment procedure, infection recurrence leads to repetitive debridement, prolonged treatment time, and increased psychological stress on patients. Patients suffered from multiple reinfection may even refuse further revision, demanding amputation as the final solution [22]. Even though the infection-free result is important in this scenario, the infection-free rates of external and hybrid fixators are still unknown.

Additionally, Ilizarov methods are associated with high rates of temporary complication and residual sequela which are difficult to avoid. As an application of distraction osteogenesis, bone transport technique were also reported with sequelae in many studies [6,23]. Residual sequelae, which remain unsolved at the end of the treatment period, are used as indicators for criteria to grade outcomes of both bone union and function [3, 24, 25]. Despite the high rate of satisfactory results (excellent and good) reported in most studies, the rate of sequela-free result (excellent), is varied. Since prognosis factors are seldom studied, it is difficult to determine those factors leading to a sequela-free result.

Thus, this systematic review was conducted to addresses the question in the treatment of tibial infected nonunion and chronic osteomyelitis.: 1) Do hybrid fixators have lower incidence of infection-free results compared to external fixators? 2) What are predictive factors of sequelae in bone transportation technique?

\section{Methods}

\section{Strategy}

The systematic review was conducted according to Preferred Reported Items for Systematic Reviews of MetaAnalyses Statement for Individual Patient Data (PRISMA-IPD) [26]. Databases including Medline, Embase, and Cochrane were searched from January 1995 until September 2018. Key words "bone transport technique," "Ilizarov," "infectious non-union," "osteomyelitis," "distraction osteogenesis," and "tibia" were combined in the search procedure. The reference lists of included studies were manually searched to avoid omissions.

\section{Eligibility criteria}

After excluding duplicates, two independent reviewers screened all remaining records based on both titles and abstracts, then screened the full text of the potentially relevant studies. Studies were considered acceptable for inclusion if the following criteria were fulfilled: (1) studies treated adult patients (more than 16 years of age) diagnosed of tibia infectious non-union or osteomyelitis; (2) studies with a minimum sample of 5 aforementioned consecutive patients were treated with multifocal bone transport technique; For IPD collection, each subgroup of fixator systems should contain no less than 5 patients. (3) main outcome of bone union and function were graded to excellent, good, fair or poor according to Paley or ASAMI classification, and recurrence of osteomyelitis or deep bone infection was recorded; (4) original articles written in English. In the cases of research on the same patient group published at the same institution, the most complete or recent data was used. Disagreements were solved by consulting a third reviewer.

\section{Data collection}

Specific information from selected papers was compiled. According to the details of Paley or ASAMI classification, the outcomes are graded by the number of sequelae: "excellent" is the outcome without sequelae, while the "good," "fair," and "poor" outcomes are associated with increasing numbers of sequelae. Herein we define those patients who received excellent results in a "sequelae free" group, while the good, fair, and poor are considered "sequelae." IPD were compiled for the following variables where available: demographic information (age, gender), number of previous operations, type of fixator, size of bone defect, length of distraction osteogenesis, time of external fixation and consolidation, healing index (time between application of fixators and consolidation divided by the length of the defect), and external fixation index (external fixation time divided by the length of defect).

\section{Statistical analysis}

The rates of infection-free outcomes were synthesized in subgroups of external fixator group or hybrid fixator group with the variance-stabilizing double arcsine transformation [27]. Heterogeneity was quantified using the $I^{2}$ statistic. The $I^{2}$ heterogeneity was degreed as follows: < 25\% low, 25 
to $50 \%$ moderate and $>50 \%$ high. Fixed-effects models were used for low and moderate heterogeneity while random-effects models for high heterogeneity. To understand the factors which impact associated sequelae, two-step method with logistic regression was used to investigate the IPD (95\% confidence interval). IPD from each study was independently analyzed in the first step to produce an estimate for each study, and then these data were analyzed. All analyses were performed using Stata (version 14.0, StataCorp, College Station, TX, USA).

\section{Results}

Based on our review, twenty-two studies with 518 patients met inclusion criteria: eleven studies with $167 \mathrm{pa}$ tients' IPD, and 11 studies with 351 patients' aggregate data (Fig. 1). Hybrid fixators were applied on 63 patients, while external fixators were applied on 454 patients (Table 1). The overall infection-free rate of bone transportation for tibia infected nonunion and chronic osteomyelitis is $96 \%$ (95\%CI: 94-98\%, Fig. 2). Significant heterogeneity existed between the groups of hybrid and external fixators ( $p=0.01$, Fig. 2 ). The infection-free rate of hybrid fixator group was $86 \%$ (95\%CI: 79-94\%, Fig. 2), while that of external fixator was $97 \%$ (95\%CI: 95-98\%, Fig. 2).

For the IPD data, the mean age of patients was 38.25 years (range from 16 to 79 years), the mean number of previous surgeries was 3.49 (range from 1 to 20). The mean size of bone defect after debridement was $5.25 \mathrm{~cm}$ (range from 1 to $12 \mathrm{~cm}$ ). The mean healing index was 1.74 months $/ \mathrm{cm}$ (range from 0.8 to 15.8 months $/ \mathrm{cm}$ ), the mean external fixator index was 1.1 months $/ \mathrm{cm}$ (range from 0.4 to 1.7 months $/ \mathrm{cm}$ ) (Table 2).

Among the variables of IPD, the number of previous operations before bone transportation had a significant impact on the sequelae of both bone union $(p=0.04)$ and function $(p<0.01)$. Longer external fixation $(p=$

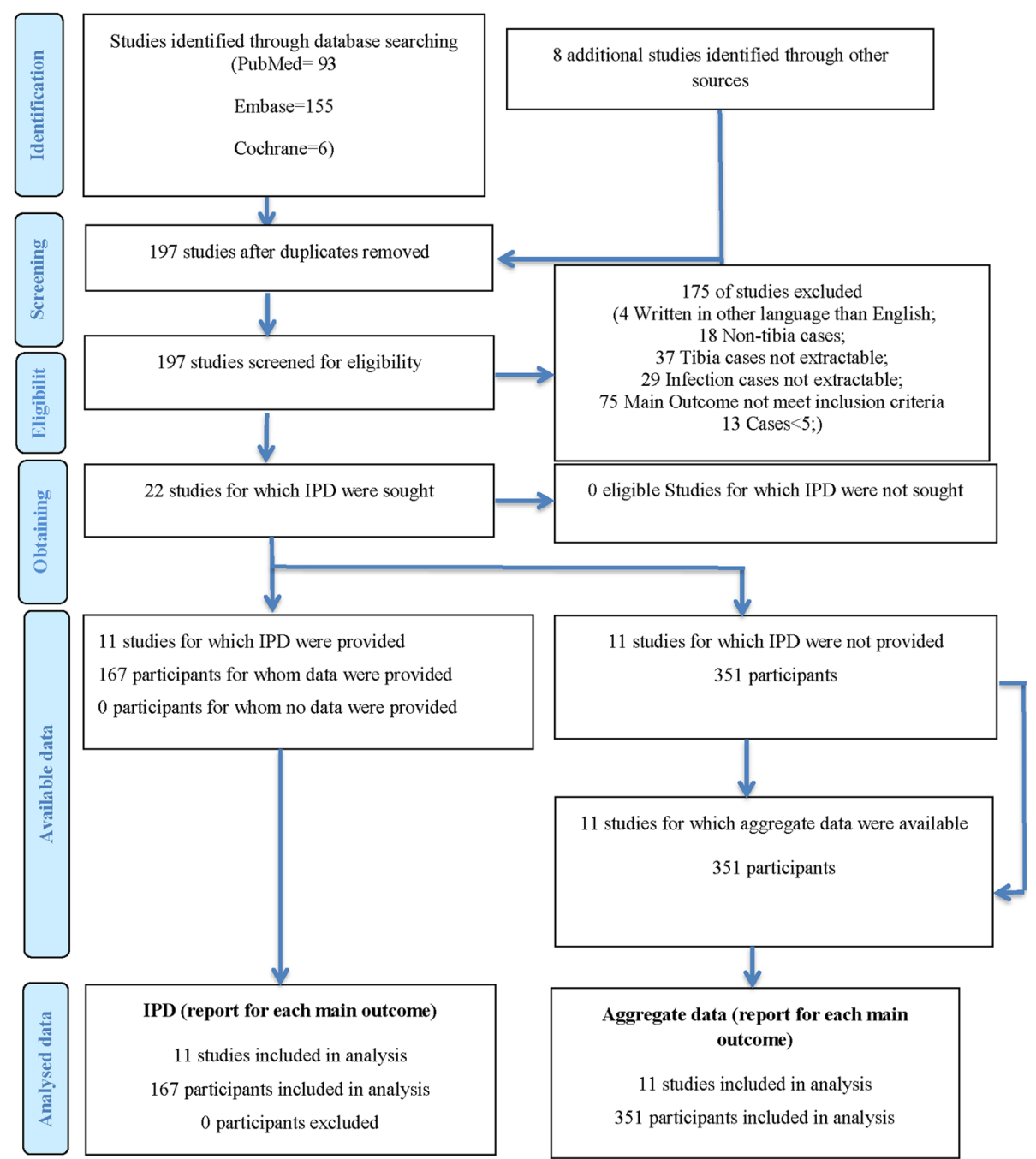

Fig. 1 PRISMA-IPD flow diagram, illustrating the identification, screening and exclusion process 
Table 1 Summary of Included Studies

\begin{tabular}{|c|c|c|c|c|c|c|c|c|c|c|c|c|}
\hline \multirow[t]{2}{*}{ ID } & \multirow[t]{2}{*}{$\begin{array}{l}\text { Data } \\
\text { type }\end{array}$} & \multirow[t]{2}{*}{$\begin{array}{l}\text { Patients } \\
\text { Number }\end{array}$} & \multicolumn{2}{|c|}{ Gender } & \multirow[t]{2}{*}{ Age(year) } & \multirow[t]{2}{*}{ Fixator System } & \multirow[t]{2}{*}{$\begin{array}{l}\text { Soft-tissue } \\
\text { Reconstruction }\end{array}$} & \multicolumn{2}{|c|}{$\begin{array}{l}\text { Satisfactory } \\
\text { Result }\end{array}$} & \multicolumn{2}{|c|}{ Sequelae-free } & \multirow[t]{2}{*}{$\begin{array}{l}\text { Infection } \\
\text { Free }\end{array}$} \\
\hline & & & Male & Female & & & & Bone & Function & Bone & Function & \\
\hline $\begin{array}{l}\text { Dendrinos } \\
1995 \text { [38] }\end{array}$ & IPD & 28 & 23 & 5 & $37.43(18 \sim 74)$ & Ilizarov EF & - & 24 & 18 & 14 & 7 & 28 \\
\hline Eralp 2016 [43] & IPD & 6 & 3 & 3 & 48.33(33 79) & Ilizarov EF; TSF & $1^{b}$ & - & 4 & - & 2 & 6 \\
\hline Khan 2015 [44] & IPD & 6 & 6 & 0 & 40.60(19 55) & \|lizarov EF & $3^{b}$ & 4 & 4 & 0 & 1 & 5 \\
\hline $\begin{array}{l}\text { Kocaoglu } \\
2006[17]\end{array}$ & IPD & 7 & 5 & 2 & $35.29(18 \sim 52)$ & Hybrid Fixator & $2^{b ; c}$ & 7 & 7 & 6 & 6 & 5 \\
\hline Lalit 2000 [40] & IPD & 16 & 16 & 0 & $30.81(17 \sim 46)$ & Ilizarov EF & - & 11 & 12 & 8 & 5 & 14 \\
\hline Liu 2012 [45] & IPD & 35 & 25 & 10 & $37.29(18 \sim 64)$ & EF & $5^{b}$ & 33 & 34 & 28 & 30 & 32 \\
\hline $\begin{array}{l}\text { Marko } 2010 \\
{[46]}\end{array}$ & IPD & 30 & 29 & 1 & $30.57(20 \sim 49)$ & \|lizarov EF & - & 29 & 27 & 19 & 13 & 30 \\
\hline Oh 2008 [16] & IPD & 10 & 10 & 0 & $46.00(18 \sim 76)$ & Hybrid Fixator & $5^{b}$ & - & 10 & - & 4 & 9 \\
\hline Oh 2013 [47] & IPD & 10 & 9 & 1 & $40.40(16 \sim 64)$ & Hybrid Fixator & $4^{b}$ & 10 & 9 & 10 & 6 & 10 \\
\hline $\begin{array}{l}\text { Panagiotis } \\
2010 \text { [48] }\end{array}$ & IPD & 6 & 5 & 1 & $34.50(21 \sim 52)$ & Ilizarov EF & $2^{b}$ & 6 & 4 & 3 & 1 & 6 \\
\hline $\begin{array}{l}\text { Zhang } 2016 \\
\text { [19] }\end{array}$ & IPD & 14 & 13 & 1 & $38.07(21 \sim 62)$ & $\begin{array}{l}\text { Mono-lateral EF; } \\
\text { Hybrid Fixators }\end{array}$ & $1^{b} ; 2^{c}$ & 14 & 11 & 12 & 8 & $5 ; 6^{\mathrm{a}}$ \\
\hline $\begin{array}{l}\text { Emara } 2008 \\
{[18]}\end{array}$ & $A D$ & 33 & 22 & 11 & 29 & $\begin{array}{l}\|_{\text {lizarov ring; Hybrid }} \\
\text { Fixators }^{\mathrm{a}}\end{array}$ & - & 33 & 28 & 32 & 25 & $16 ; 16^{a}$ \\
\hline $\begin{array}{l}\text { McNally } \\
2017 \text { [22] }\end{array}$ & $A D$ & 18 & - & - & - & Nlizarov ring & - & 14 & 17 & 13 & 13 & 18 \\
\hline Peng 2015 [49] & $A D$ & 58 & 38 & 20 & 29.4(18 51) & Ilizarov ring & - & 53 & 46 & 30 & 28 & 57 \\
\hline Rohilla 2016 [4] & $A D$ & 70 & 62 & 8 & $31.25(18 \sim 65)$ & $\begin{array}{l}\text { Mono-lateral EF; Ring } \\
\text { EF }\end{array}$ & 0 & 62 & 55 & 35 & 28 & 35 \\
\hline Sadek 2016 [5] & $A D$ & 14 & 12 & 2 & 29.50 & Ring EF & 8 & 14 & 8 & 11 & 8 & 14 \\
\hline $\begin{array}{l}\text { Tetsworth } \\
2017[7]\end{array}$ & $A D$ & 21 & 18 & 3 & $38.2(18 \sim 66)$ & Ring/llizarov EF & - & 20 & 20 & 15 & 14 & 21 \\
\hline Tong 2017 [50] & $A D$ & 13 & - & - & - & $\begin{array}{l}\text { Mono-lateral EF; } \\
\text { Ilizarov EF }\end{array}$ & - & 10 & 5 & 5 & 1 & 9 \\
\hline Yin 2014 [51] & $A D$ & 72 & - & - & - & Ilizarov EF & - & 63 & 52 & 46 & 25 & 72 \\
\hline Eralp 2012 [13] & $A D$ & 15 & 14 & 3 & $39(25 \sim 69)$ & Hybrid Fixator & - & 14 & 15 & 10 & 10 & 14 \\
\hline $\begin{array}{l}\text { Gupta } 2018 \\
\text { [52] }\end{array}$ & $A D$ & 14 & 13 & 1 & 38.1 & Hybrid Fixator & $1^{b}$ & 14 & 14 & 14 & 8 & 13 \\
\hline $\begin{array}{l}\text { Madhusudhan } \\
2008 \text { [53] }\end{array}$ & $A D$ & 22 & - & - & - & Ilizarov EF & $4^{b}$ & 13 & 5 & 5 & 1 & 16 \\
\hline
\end{tabular}

AD Aggregate data, IPD Individual participant data, EF External Fixators, TSF Taylor Spatial Frame; a: Early change from external fixators to internal fixators; b: Softtissue flap; c: Skin graft

0.015) was associated with a greater chance of functional sequelae. Age, size of bone defect, and length of bone distraction did not have significant impacts on the sequelae of bone union or function (Table 3).

\section{Discussion}

Infection relapse of tibial infectious nonunion and chronic osteomyelitis is common, because most causative bacteria are antibiotic-resistant, making it difficult to completely eradicate their populations with common prophylaxis $[28,29]$. The affected patients tend to incur more than one surgery before achieving a successful infection-free result. Bone transportation techniques with external or hybrid fixator systems have been proved versatile to deal with this clinical challenge. However, the infection-free rates of these two fixator systems remain unknown and seldom compared. In the present meta-analysis, hybrid fixators were found to have a higher rate of infection recurrence compared to external fixators (Fig. 2).

In bone transportation technique, the choice of fixator systems depends on the treatment philosophy of long bone infection [17]. However, this philosophy has evolved in recent decades, from "the infection would burn on the fire of the bone regeneration," by Ilizarov, to "the only cure for osteomyelitis is radical debridement," 


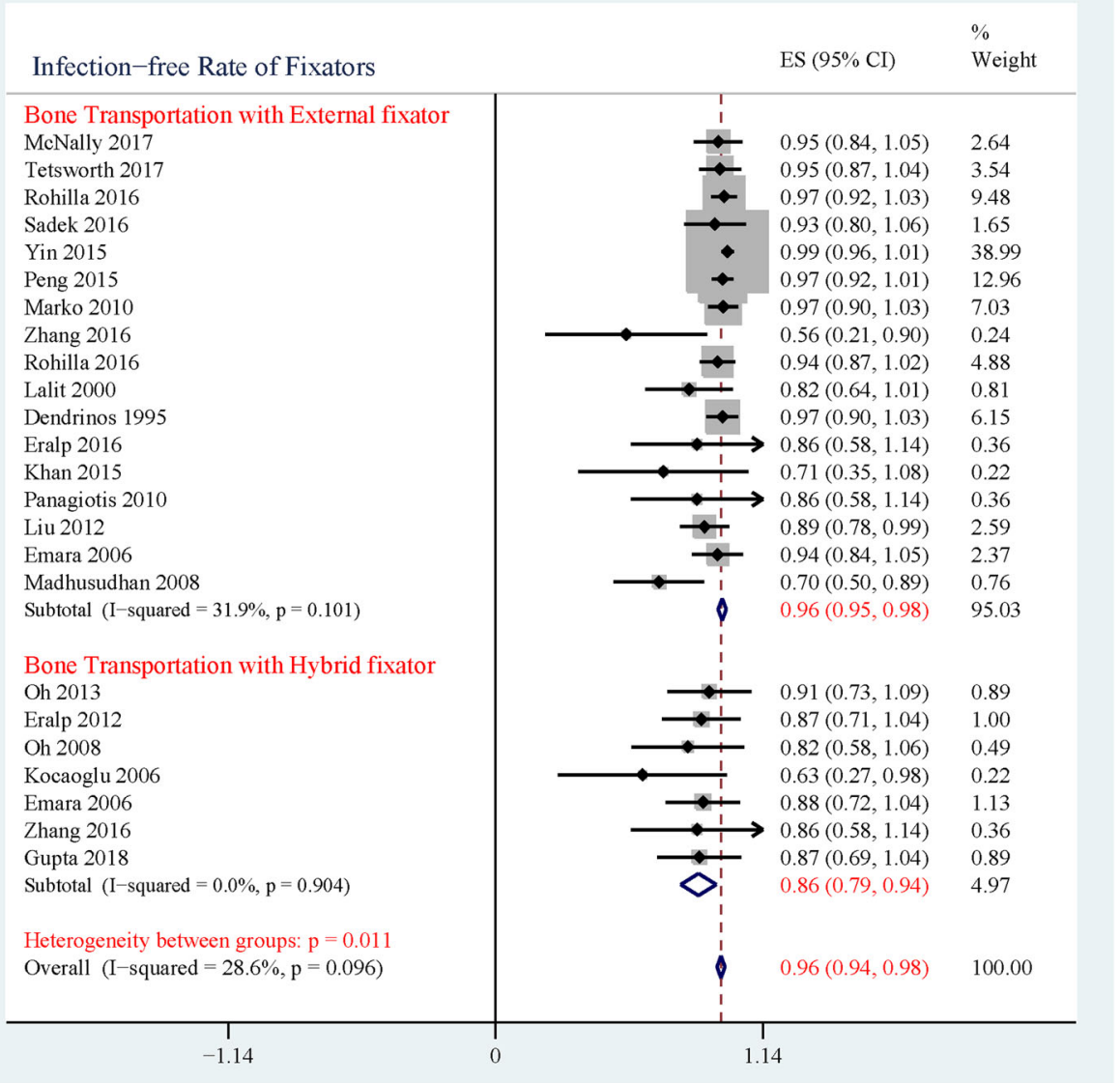

Fig. 2 Forest plot of infection-free rate of fixators used in bone transportation

by Cierny [30]. The later concept has greater amounts supportive evidence recently and is more widely accepted [31]. In most cases the infected tissue was extensively excised until live and bleeding bone (paprika sign), with which a large amount of bacterial burden would be removed. Based on this prerequisite it seems safe to implement internal fixators during or after the distraction period to overcome the disadvantage of external fixation [17]. However, the risk of infection recurrence comes along with internal fixators still exists. The reason is that debridement alone is not sufficient to sterilize the operative site. Small bacterial colonies can be displaced

Table 2 Summary of IPD

\begin{tabular}{|c|c|c|c|c|c|c|c|c|}
\hline ID & $\begin{array}{l}\text { Previous } \\
\text { Surgery }\end{array}$ & $\begin{array}{l}\text { Bone } \\
\text { defect }(\mathrm{cm})\end{array}$ & $\begin{array}{l}\text { Bone } \\
\text { graft }\end{array}$ & $\begin{array}{l}\text { Length of } \\
\text { distraction }(\mathrm{cm})\end{array}$ & $\begin{array}{l}\text { External Fixation } \\
\text { Time (weeks) }\end{array}$ & $\begin{array}{l}\text { External Fixation } \\
\text { Index (months/cm) }\end{array}$ & Heal Time (weeks) & $\begin{array}{l}\text { Heal Index } \\
\text { (months/cm) }\end{array}$ \\
\hline Dendrinos 1995 & $4.04(1 \sim 20)$ & $6.14 \pm 2.68$ & 3 & $5.54 \pm 2.46$ & $41.46(21.50 \sim 77.40)$ & $1.95 \pm 0.74$ & $27.77(17.20 \sim 43.00)$ & $1.35 \pm 0.64$ \\
\hline Eralp 2016 & & - & - & $3.00 \pm 2.61$ & $32.26(21.43 \sim 42.86)$ & $1.04 \pm 0.11$ & - & - \\
\hline Khan 2015 & $2.00(1 \sim 3)$ & $2.82 \pm 0.95$ & - & $2.82 \pm 0.95$ & - & - & $72.80(32.00 \sim 124.00)$ & $7.77 \pm 6.38$ \\
\hline Kocaoglu 2006 & $5.29(1 \sim 20)$ & $7.00 \pm 1.83$ & 7 & - & $12.63(8.00 \sim 20.00)$ & - & $33.09(21.45 \sim 55.77)$ & $1.07 \pm 0.21$ \\
\hline Lalit 2000 & $2.38(1 \sim 5)$ & $7.71 \pm 2.30$ & 3 & - & - & - & - & - \\
\hline Liu 2012 & $2.69(1 \sim 6)$ & $3.55 \pm 1.47$ & 2 & $7.81 \pm 2.21$ & - & - & - & $1.37 \pm 0.12$ \\
\hline Marko 2010 & - & $6.87 \pm 1.76$ & 1 & $6.53 \pm 1.53$ & - & $1.48 \pm 0.07$ & $17.86(14.00 \sim 20.00)$ & $1.03 \pm 0.06$ \\
\hline Oh 2008 & - & $5.75 \pm 2.89$ & 10 & - & - & $0.80 \pm 0.27$ & - & $2.09 \pm 0.61$ \\
\hline Oh 2013 & - & $5.91 \pm 1.96$ & 10 & - & - & $0.45 \pm 0.08$ & - & $2.15 \pm 0.23$ \\
\hline Panagiotis 2010 & $5.00(1 \sim 6)$ & $6.67 \pm 3.20$ & - & - & $33.67(17.00 \sim 59.00)$ & - & - & - \\
\hline Zhang 2016 & $4.36(1 \sim 7)$ & - & 6 & $5.91 \pm 1.24$ & $41.43(23.00 \sim 57.00)$ & - & $44.86(31.00 \sim 61.00)$ & $1.87 \pm 0.59$ \\
\hline
\end{tabular}


Table 3 Factors on Sequelae-free Result of Bone and Function

\begin{tabular}{|c|c|c|c|c|c|c|c|c|}
\hline \multirow[t]{2}{*}{ Variables } & \multicolumn{4}{|c|}{ Sequelae-free Bone Result } & \multicolumn{4}{|c|}{ Sequelae-free Function Result } \\
\hline & Num of studies & Odds Ratio (95\% Cl) & $P$ value & $P^{2}(\%)$ & Num of studies & Odds Ratio (95\% Cl) & $P$ value & $P^{2}(\%)$ \\
\hline Age & 7 & $0.995(0.961$ to 1.031$)$ & 0.789 & $0.0 \%$ & 10 & $0.969(0.936$ to 1.003$)$ & 0.075 & $0.0 \%$ \\
\hline Previous Surgery Times & 5 & $0.687(0.480$ to 0.984$)$ & 0.040 & $37.5 \%$ & 4 & $0.338(0.189$ to 0.603$)$ & 0.000 & $0.0 \%$ \\
\hline Bone defect & 6 & $1.030(0.842$ to 1.260$)$ & 0.776 & $0.0 \%$ & 7 & $0.828(0.657$ to 1.043$)$ & 0.109 & $3.2 \%$ \\
\hline Length of Distraction & 4 & $0.979(0.605$ to 1.583$)$ & 0.930 & $49.6 \%$ & 5 & $0.919(0.664$ to 1.273$)$ & 0.613 & $14.8 \%$ \\
\hline Time of External Fixation & 4 & $0.977(0.924$ to 1.032$)$ & 0.404 & $0.0 \%$ & 4 & $0.899(0.825$ to 0.979$)$ & 0.015 & $0.0 \%$ \\
\hline Time of Bone Union & 4 & $0.962(0.872$ to 1.060$)$ & 0.431 & $0.0 \%$ & 4 & $0.836(0.740$ to 0.954$)$ & 0.004 & $0.0 \%$ \\
\hline
\end{tabular}

during the debridement procedure even under most careful cleaning [32]. If internal fixator is subsequently implanted, the residual bacteria on the device surface could form a biofilm, leading to infection recurrence. Consistently, in this research hybrid fixators showed potential inferior infection-free result than external fixators, indicating the internal fixators may not be appropriate in this specific scenario.

Similarly, Bose suggested that external fixators are safer than internal fixation for an infected nonunion fracture. Though all the infected bone and unhealthy enveloping soft tissue were completely excised, four of six patients had infection recurrence after internal fixation [21]. Liodakis found that in cases where an intramedullary rod was involved, there was a greater rate of infection recurrence than in cases of external fixation when dealing with infected post-traumatic tibia. He recommended the post-traumatic bone defects with chronic infection should only be fixed by external frame [8]. Besides providing a potential harbor for residual bacteria, the intramedullary nails also facilitate the spread of the pin tract infection along implants [33].To avoid internalrelated infection recurrence, internal fixators can be applied at a later time, not immediately after debridement. In this way, when the distraction phase is over, the external fixators are removed and replaced by internal fixators. Zhang conducted early osteosynthesis with plate or intramedullary nail once two bone ends meet at the dock site. and no reinfection was noted [19]. However, Emara suggested this method still has risk of infection recurrence; in his study infection recurrence occurred in one patient who received early nailing, and the intramedullary nail was changed to an Ilizarov fixator until final union [18]. Last but not least, patients' immunologic status has an impact on the infection-free rates. Within the hybrid fixator treatment group in Oh's study, a diabetes mellitus patient was complicated with infectious recurrence [15]. Even though no statistical conclusion is draw due to the small sample size, patients with inferior immunologic function likely have a greater risk of infection recurrence and may be better suited for treatment by external fixator, which is safer.
Complete coverage of soft tissue is important to control and prevent infection. The early coverage of soft tissue may provide nutrition, obliterate dead space, facilitate local immunologic defense, and antibiotic delivery [22]. In most cases, soft tissue reconstruction was done empirically according to surgeons' evaluation and preference. In the current review musculocutaneous flaps and skin grafts were the most commonly used methods to compensate for lost soft tissue and achieve satisfactory coverage (Table 1). However, due to the insufficient reported data, the hypothesis that soft reconstruction could increase infection-free rates, and the implementation of internal fixators could undermine the soft tissue, cause poor vascularity, and consequently reduce infection-free rates, remains to be investigated. Oh believed implantation of a locking plate would not compromise the surrounding soft tissue because of minimally invasive or percutaneous techniques [27]. Even though more thorough evidence is warranted to draw a conclusion for the role of soft tissue, proper reconstruction of surrounding soft tissue is still a great concern when surgical plans are made.

Despite these observations, the advantages of hybrid fixators are still remarkable. The external fixator could be removed once defect ends meet with combined fixation. This shortens the timeframe for potential distraction-related complications. Additionally, early removal of external fixators is more comfortable for the patients [17]. It is well known that the long-time external fixation imposes psychosocial hardships and disruption in daily lives to patients. The bulky external fixators interrupt activities of daily living (ADL) as well as leisure and sport activities [24]. Combining internal fixators facilitates the early return to ADL without the need for wearing external apparatus. Similarly, it can also allow early rehabilitation and prevent related joint stiffness [17]. Hybrid fixators demonstrated the highest success rate compared with external fixators alone for bone healing in the case of limb salvage of long bone defects [12]. However, for the infected cases, the higher potential risk of infection recurrence is more worrisome and serious than uncomfortableness. Notably, internal fixators used in all included studies were traditional internal implants without antibiotic surface modification. 
Antibiotic-coated implants have gained increasing interest recently. These novel surface coatings have been successfully used in the treatment of osteomyelitis and long bone infectious nonunion [28, 34-37]. This method could provide both infection control, or prophylaxis, and osseous stability simultaneously $[28,34]$. Further research in this area is necessary towards a more comprehensive understanding of the long-term success of such surface coatings.

Infection recurrence leads to multiple operations [17, 38]. Many patients with tibia infection suffer from repeated surgeries before seeking the final bone transport treatment. In the present analysis, the number of previous operations is a predictive factor of prognosis for bony union ( $p=0.04$, Table 3 ) and functional restoration $(p<0.01$, Table 3$)$ : a greater number of previous surgeries are correlated with a greater chance of sequelae. Several reason could explain this result. First, the repeatedly debridement and surgery would lead to prolonged hospital stays, loss of soft and bone tissue, impaired function of the affected limbs, increased pain, and a poor quality of life [39]. Additionally, the repeated operation could cause more scar tissue and subsequently poor soft tissue flexibility, which cause difficult exposure for the subsequent procedures $[40,41]$. The consequent surgeries pose a high risk of poor outcome, as well as financial and psychological burdens to patients. Number of previous surgeries is a useful indicator to predict the treatment outcome for the patients with repeated revision. Therefore, it is important to meticulously design a surgery treatment plan and conduct limb salvage by an experienced multidisciplinary team in order to minimize the need for further unexpected operations.

The duration of external fixation has been suspected to be associated with a worse functional result. However, it is hard to make a definitive conclusion because of small sample sizes in previous research. In the present study, by pooling the IPD to increase sample size, the time of external fixation is found to be associated a greater risk of functional sequelae $(p=0.015$, Table 3$)$. In cases of extended duration of external fixation patients tend to suffer more joint stiffness, muscle dystrophy and significant pain. Additionally, more pin-related infections are also involved [6]. Hence, a shortened external frame time is necessary to reduce functional complications related to external fixators and improve patient outcomes $[14,16,17]$. To shorten external frame time of distraction, one option is to add more transport segments in large bone defects. Paley and Maar suggested trifocal bone transport when the bone defect is larger than $10 \mathrm{~cm}$ [24], while Rozbruch and Zhang set the criterion for trifocal transport at greater than $6 \mathrm{~cm}$ [42]. All trifocal patients in their studies had reduced distraction times. The trifocal bone transport could double the distraction speed because two-level osteotomies divided lengthening (and healing) into two locations [14]. To shorten the duration of dock consolidation, combining an internal implant could facilitate the early removal of external fixators and rehabilitation. However, there is a potential risk of infections recurrence, which should be considered in treatment and surgical planning. If the antibiotic-coated internal implants could achieve satisfactory control and prophylaxis of infection, it is an effective choice to manage cases of tibia infectious nonunion and osteomyelitis.

This is the first study to summary the infection-free results of bone transport techniques with external and hybrid fixators for tibia infectious nonunion and chronic osteomyelitis, and the first to determine factors which predict bone and function sequela. Here, hybrid technique involved traditional internal fixators showed more potential risk of infection recurrence than external groups. The number of previous operations and the duration of external fixation were confirmed associated with greater risk of sequelae. However, the results of this analysis should be interpreted carefully because of the limitations of this study. First, most of the included studies are retrospective with small sample sizes. Second, though the principle of the criterion of the ASIMI and Paley classifications are the same, in which classifications are graded by number of sequelae, difference exists in their criterion. Third, the included studies have obvious heterogeneity even though selection criteria were set. In the future prospective and large-scale clinical research is necessary to better understand the factors influencing patient outcomes.

\section{Conclusions}

Bone transport technique is an established treatment to deal with segmental bone defects due to infection. Hybrid fixator system combining traditional internal and external fixators may be associated with a greater risk of infection recurrence; antibiotic-coated internal implants maybe a promising choice to circumvent this well-known issue. Additionally, we have demonstrated that number of previous operations as well as duration of external fixation are useful prognostic indicators for predicting outcomes. To achieve successful healing and functional results, meticulous surgical planning is necessary in order to avoid additional surgeries and long external fixation times.

\section{Abbreviations \\ AD: Aggregate Data; ADL: Activities of Daily Living; EF: External Fixator; IPD: Individual Patient Data; PRISMA-IPD: Preferred Reported Items for Systematic Reviews of Meta-Analyses Statement for Individual Patient Data; TSF: Taylor Spatial Frame}

\section{Acknowledgements}

Not applicable.

\section{Funding}

This research was supported by Sichuan Science and Technology Department (2018SZ0145) and Sichuan Health and Family Planning Commission (17PJ128). 
The funding body did not take part in the design of the study and collection, analysis, and interpretation of data and in writing the manuscript.

\section{Availability of data and materials}

The datasets used and/or analysed during the current study are available from the corresponding author on reasonable request.

\section{Authors' contributions}

ZZ and Y-H W searched and screened papers as well as abstracted data. ZZ and WBS did statistic work and wrote the paper. WL solved disagreement of paper's selection. WL and GW designed the whole study and guided the whole research. All authors have read and approved the manuscript and agree to publish.

\section{Ethics approval and consent to participate}

Not applicable.

\section{Consent for publication}

Not applicable.

\section{Competing interests}

The authors declare that they have no competing interests.

\section{Publisher's Note}

Springer Nature remains neutral with regard to jurisdictional claims in published maps and institutional affiliations.

\section{Author details}

'Department of Orthopedics, West China Hospital, Sichuan University, No. 37, Guoxue Lane, Wuhou District, Chengdu 610041, Sichuan Province, China. 2Department of Biologic and Materials Sciences, School of Dentistry, University of Michigan, Ann Arbor, USA. ${ }^{3}$ Department of Neonatology, Beijing Gynecology \& Obstetrics Hospital, Capital Medical University, Beijing, China. ${ }^{4}$ Department of Gynecology, West China Second Hospital, Sichuan University, Chengdu, China.

\section{Received: 11 October 2018 Accepted: 27 November 2018}

\section{Published online: 13 December 2018}

\section{Reference}

1. Hak DJ, Fitzpatrick D, Bishop JA, Marsh JL, Tilp S, Schnettler R, Simpson H, Alt V. Delayed union and nonunions: epidemiology, clinical issues, and financial aspects. Injury. 2014:45(Suppl 2):S3-7.

2. Brinker MR, Hanus BD, Sen M, O'Connor DP. The devastating effects of tibial nonunion on health-related quality of life. J Bone Joint Surg Am. 2013; 95(24):2170-6

3. Yin P, Li T, Zhang L, Wang G, Li J, Liu J, Zhou J, Zhang Q, Tang P. Infected nonunion of tibia and femur treated by bone transport. J Orthop Surg Res. 2015:10:49.

4. Rohilla R, Wadhwani J, Devgan A, Singh R, Khanna M. Prospective randomised comparison of ring versus rail fixator in infected gap nonunion of tibia treated with distraction osteogenesis. Bone Joint J. 2016;98-B(10): 1399-405.

5. Sadek AF, Laklok MA, Fouly EH, Elshafie M. Two stage reconstruction versus bone transport in management of resistant infected tibial diaphyseal nonunion with a gap. Arch Orthop Trauma Surg. 2016;136(9):1233-41.

6. Paley D. Problems, obstacles, and complications of limb lengthening by the Ilizarov technique. Clin Orthop Relat Res. 1990:(250):81-104.

7. Tetsworth K, Paley D, Sen C, Jaffe M, Maar DC, Glatt V, Hohmann E, Herzenberg JE. Bone transport versus acute shortening for the management of infected tibial non-unions with bone defects. Injury. 2017:48(10):2276-84.

8. Liodakis E, Kenawey M, Krettek C, Wiebking U, Hankemeier S. Comparison of 39 post-traumatic tibia bone transports performed with and without the use of an intramedullary rod: the long-term outcomes. Int Orthop. 2011; 35(9):1397-402.

9. Patzakis MJ, Zalavras CG. Chronic posttraumatic osteomyelitis and infected nonunion of the tibia: current management concepts. J Am Acad Orthop Surg. 2005;13(6):417-27.

10. Paley D. Treatment of tibial nonunion and bone loss with the llizarov technique. Instr Course Lect. 1990;39:185-97.
11. Gubin AV, Borzunov DY, Malkova TA. The llizarov paradigm: thirty years with the llizarov method, current concerns and future research. Int Orthop. 2013, 37(8):1533-9.

12. Kadhim M, Holmes L Jr, Gesheff MG, Conway JD. Treatment options for nonunion with segmental bone defects: systematic review and quantitative evidence synthesis. J Orthop Trauma. 2017;31(2):111-9.

13. Eralp L, Kocaoglu M, Polat G, Bas A, Dirican A, Azam ME. A comparison of external fixation alone or combined with intramedullary nailing in the treatment of segmental tibial defects. Acta Orthop Belg. 2012;78(5):652-9.

14. Zhang Y, Wang Y, Di J, Peng A. Double-level bone transport for large posttraumatic tibial bone defects: a single Centre experience of sixteen cases. Int Orthop. 2018;42(5):1157-64.

15. Oh CW, Apivatthakakul T, Oh JK, Kim JW, Lee HJ, Kyung HS, Baek SG, Jung $\mathrm{GH}$. Bone transport with an external fixator and a locking plate for segmental tibial defects. Bone Joint J. 2013:95-B(12):1667-72.

16. Oh CW, Song HR, Roh JY, Oh JK, Min WK, Kyung HS, Kim JW, Kim PT, Ihn JC. Bone transport over an intramedullary nail for reconstruction of long bone defects in tibia. Arch Orthop Trauma Surg. 2008;128(8):801-8.

17. Kocaoglu M, Eralp L, Rashid HU, Sen C, Bilsel K. Reconstruction of segmental bone defects due to chronic osteomyelitis with use of an external fixator and an intramedullary nail.[Reprint in J Bone Joint Surg Am. 2007 Sep;89 Suppl 2 Pt.2:183-95; PMID: 17768214]. J Bone Joint Surg Am. 2006;88(10):2137-45.

18. Emara KM, Allam MF. Ilizarov external fixation and then nailing in management of infected nonunions of the tibial shaft. J Trauma. 2008; 65:685-91.

19. Zhang S, Wang H, Zhao J, Xu P, Shi H, Mu W. Treatment of post-traumatic chronic osteomyelitis of lower limbs by bone transport technique using mono-lateral external fixator: follow-up study of 18 cases. J Orthop Sci. 2016;21(4):493-9.

20. Li Z, Zhang X, Duan L, Chen X. Distraction osteogenesis technique using an intramedullary nail and a monolateral external fixator in the reconstruction of massive postosteomyelitis skeletal defects of the femur. Canadian journal of surgery Journal canadien de chirurgie. 2009; 52(2):103-11.

21. Bose D, Kugan R, Stubbs D, McNally M. Management of infected nonunion of the long bones by a multidisciplinary team. Bone Joint J. 2015;97$B(6): 814-7$.

22. McNally M, Ferguson J, Kugan R, Stubbs D. Ilizarov treatment protocols in the Management of Infected Nonunion of the tibia. J Orthop Trauma. 2017 31(Suppl 5):S47-54

23. Yin P, Ji Q, Li T, Li J, Li Z, Liu J, Wang G, Wang S, Zhang L, Mao Z, et al. A systematic review and meta-analysis of Ilizarov methods in the treatment of infected nonunion of tibia and femur. PLoS One. 2015;10(11):e0141973.

24. Paley D, Maar DC. Ilizarov bone transport treatment for tibial defects. J Orthop Trauma. 2000;14(2):76-85

25. Paley D, Catagni MA, Argnani F, Villa A, Benedetti GB, Cattaneo R. Ilizarov treatment of tibial nonunions with bone loss. Clin Orthop Relat Res. 1989; (241):146-65.

26. Stewart LA, Clarke M, Rovers M, Riley RD, Simmonds M, Stewart G, Tierney JF. Group P-ID: preferred reporting items for systematic review and metaanalyses of individual participant data: the PRISMA-IPD statement. Jama. 2015:313(16):1657-65.

27. Freeman MF, Tukey JW. Transformations related to the angular and the square root. The Annals of Mathematical Statistics. 1950;21(4):607-11.

28. Barger J, Fragomen AT, Rozbruch SR. Antibiotic-coated interlocking intramedullary nail for the treatment of long-bone osteomyelitis. JBJS Rev. 2017;5(7):e5.

29. Metsemakers WJ, Kuehl R, Moriarty TF, Richards RG, Verhofstad MHJ, Borens O, Kates S, Morgenstern M. Infection after fracture fixation: current surgical and microbiological concepts. Injury. 2018;49(3):511-22.

30. Cierny G 3rd. Infected tibial nonunions (1981-1995). The evolution of change. Clin Orthop Relat Res. 1999;360:97-105.

31. Simpson AH, Deakin M, Latham JM. Chronic osteomyelitis. The effect of the extent of surgical resection on infection-free survival. J Bone Joint Surg Br. 2001:83(3):403-7.

32. Winkler $H$, Haiden P. Treatment of chronic bone infection. Oper Tech Orthop. 2016:26(1):2-11.

33. Clasper JC, Stapley SA, Bowley DM, Kenward CE, Taylor V, Watkins PE. Spread of infection, in an animal model, after intramedullary nailing of an infected external fixator pin track. J Orthop Res. 2001;19(1):155-9. 
34. Yu X, Wu H, Li J, Xie Z. Antibiotic cement-coated locking plate as a temporary internal fixator for femoral osteomyelitis defects. Int Orthop. 2017:41(9):1851-7.

35. Koury KL, Hwang JS, Sirkin M. The antibiotic nail in the treatment of long bone infection: technique and results. The Orthopedic clinics of North America. 2017:48(2):155-65.

36. Thonse R, Conway JD. Antibiotic cement-coated nails for the treatment of infected nonunions and segmental bone defects. J Bone Joint Surg Am. 2008;90(Suppl 4):163-74.

37. Qiang Z, Jun PZ, Jie XJ, Hang L, Bing LJ, Cai LF. Use of antibiotic cement rod to treat intramedullary infection after nailing: preliminary study in 19 patients. Arch Orthop Trauma Surg. 2007;127(10):945-51.

38. Dendrinos GK, Kontos S, Lyritsis E. Use of the llizarov technique for treatment of non-union of the tibia associated with infection. J Bone Joint Surg Am. 1995:77(6):835-46.

39. Barker $\mathrm{KL}$, Lamb SE, Simpson AH. Functional recovery in patients with nonunion treated with the llizarov technique. J Bone Joint Surg Br. 2004;86(1):81-5.

40. Maini L, Chadha M, Vishwanath J, Kapoor S, Mehtani A, Dhaon BK. The \|lizarov method in infected nonunion of fractures. Injury. 2000;31(7):509-17.

41. Ma CH, Chiu YC, Tsai KL, Tu YK, Yen CY, Wu CH. Masquelet technique with external locking plate for recalcitrant distal tibial nonunion. Injury. 2017; 48(12):2847-52.

42. Robert Rozbruch S, Weitzman AM, Tracey Watson J, Freudigman P, Katz HV, llizarov S. Simultaneous treatment of tibial bone and soft-tissue defects with the llizarov method. J Orthop Trauma. 2006;20(3):197-205.

43. Eralp IL, Kocaoglu M, Dikmen G, Azam ME, Balci HI, Bilen FE. Treatment of infected nonunion of the juxta-articular region of the distal tibia. Acta Orthop Traumatol Turc. 2016;50(2):139-46.

44. Khan MS, Rashid H, Umer M, Qadir I, Hafeez K, lqbal A. Salvage of infected non-union of the tibia with an llizarov ring fixator. J Orthop Surg (Hong Kong). 2015;23(1):52-5

45. Liu T, Yu X, Zhang X, Li Z, Zeng W. One-stage management of posttraumatic tibial infected nonunion using bone transport after debridement. Turkish Journal of Medical Sciences. 2012;42(6):1111-20.

46. Bumbasirevic M, Tomic S, Lesic A, Milosevic I, Atkinson HD. War-related infected tibial nonunion with bone and soft-tissue loss treated with bone transport using the Ilizarov method. Arch Orthop Trauma Surg. 2010; 130(6):739-49.

47. Oh CW, Apivatthakakul T, Oh JK, Kim JW, Lee HJ, Kyung HS, Baek SG, Jung $\mathrm{GH}$ : Bone transport with an external fixator and a locking plate for segmental tibial defects. Bone and Joint Journal 2013, 95 B(12):1667-1672.

48. Megas P, Saridis A, Kouzelis A, Kallivokas A, Mylonas S, Tyllianakis M. The treatment of infected nonunion of the tibia following intramedullary nailing by the llizarov method. Injury. 2010;41(3):294-9.

49. Peng J, Min L, Xiang Z, Huang F, Tu C, Zhang H. Ilizarov bone transport combined with antibiotic cement spacer for infected tibial nonunion. Int $J$ Clin Exp Med. 2015;8(6):10058-65.

50. Tong K, Zhong Z, Peng Y, Lin C, Cao S, Yang YP, Wang G. Masquelet technique versus llizarov bone transport for reconstruction of lower extremity bone defects following posttraumatic osteomyelitis. Injury. 2017.

51. Yin P, Zhang Q, Mao Z, Li T, Zhang L, Tang P. The treatment of infected tibial nonunion by bone transport using the llizarov external fixator and a systematic review of infected tibial nonunion treated by llizarov methods. Acta Orthop Belg. 2014;80(3):426-35.

52. Gupta S, Malhotra A, Mittal N, Garg SK, Jindal R, Kansay R. The management of infected nonunion of tibia with a segmental defect using simultaneous fixation with a monorail fixator and a locked plate. Bone Joint J. 2018:100b(8):1094-9.

53. Madhusudhan TR, Ramesh B, Manjunath K, Shah HM, Sundaresh DC, Krishnappa N. Outcomes of Ilizarov ring fixation in recalcitrant infected tibial non-unions - a prospective study. Journal of trauma management \& outcomes. 2008;2(1):6.

Ready to submit your research? Choose BMC and benefit from:

- fast, convenient online submission

- thorough peer review by experienced researchers in your field

- rapid publication on acceptance

- support for research data, including large and complex data types

- gold Open Access which fosters wider collaboration and increased citations

- maximum visibility for your research: over $100 \mathrm{M}$ website views per year

At $\mathrm{BMC}$, research is always in progress.

Learn more biomedcentral.com/submissions 